\title{
PROBLEMÁTICA Y CONOCIMIENTO ACTUAL DE LAS TEFRAS TIERRA BLANCA JOVEN EN EL ÁREA METROPOLITANA DE SAN SALVADOR, EL SALVADOR
}

\author{
PROBLEMATIC AND CURRENT KNOWLEDGE OF THE TIERRA BLANCA JOVEN \\ TEPHRAS IN THE METROPOLITAN AREA OF SAN SALVADOR, EL SALVADOR
}

\author{
José A. Chávez ${ }^{1,2 *}$, Walter Hernández ${ }^{3} \&$ Lubomir Kopecky $^{4}$ \\ ${ }^{1}$ Oficina de Planificación del Área Metropolitana de San Salvador (OPAMSS), \\ San Salvador, El Salvador. \\ ${ }^{2}$ Czech Technical University in Prague, Faculty of Civil Engineering, \\ Department of Geotechnics, Czech Republic. \\ ${ }^{3}$ Dirección General del Observatorio Ambiental. Colonia y Avenida Las \\ Mercedes, instalaciones ISTA, San Salvador, El Salvador \\ ${ }^{4}$ Czech Technical University in Prague, Faculty of Civil Engineering, \\ Department of Mechanics, Czech Republic. \\ *Autor para contacto: jose.alexander.chavez.hernandez@fsv.cvut.cz
}

(Recibido: 30/07/2012 ; aceptado: 17/12/2012)

\begin{abstract}
Currently the Metropolitan Area of San Salvador (AMSS) is experimenting serious problems of mass movements, erosion, collapse or settlements, phenomena that in El Salvador are popularly encompassed by the term "carcavas". This problematic is presented mainly in the volcanic tephras Tierra Blanca Joven (TBJ), product of the last plinian eruption of Ilopango Caldera, whose products are an intercalation of pyroclastic fall, flows and surge. The tephras are unsaturated and the geotechnical information shows a decrease of shear strength and collapse when saturated. To characterize properly this material is important to know the relationship of moisture content with the volume changes and apparent cohesion, which are related to suction and cementation. The understanding of the behavior of the geological materials can help in running slope stability simulations and geotechnical design in general.

Keywords: Tierra Blanca, geotechnical, unsaturated, suction, collapsible, erosion, mass movement.
\end{abstract}

RESUMEN: En la actualidad el Área Metropolitana de San Salvador experimenta problemas graves de movimientos de ladera, erosión, colapso o asentamientos del terreno; fenómenos que son englobados popularmente en El Salvador por el término "cárcavas". Esta problemática se presenta principalmente en las tefras volcánicas llamadas Tierra Blanca Joven (TBJ) producto de la última erupción pliniana de la Caldera de Ilopango, cuyos productos son una intercalación 
de estratos de piroclastos de caída, flujos y oleadas piroclásticos. Las tefras son parcialmente saturadas y la información geotécnica muestra la disminución de resistencia al corte y colapso al ser saturadas. Para caracterizar adecuadamente este material es necesario conocer la relación del contenido de humedad con los cambios de volumen y la cohesión aparente, que puede estar relacionada a la succión y a cementación. El entendimiento del comportamiento de los materiales geológicos puede ayudar en la simulación de estabilidad de taludes y diseño geotécnico en general.

Palabras clave: Tierra Blanca geotecnia, parcialmente saturado, succión, colapsable, erosión, movimiento de ladera.

\section{INTRODUCCIÓN}

Entre los problemas que se observan frecuentemente en el Área Metropolitana de San Salvador (AMSS), se pueden mencionar fenómenos como movimientos de ladera, inundaciones, lluvias intensas, terremotos, erosión intensa, intervención antrópica desordenada, asentamientos y colapsos (Rose et al., 2004; Jibson et al. 2004; González et al. 2004). Todos los años la problemática mencionada anteriormente se ve presente en menor o mayor medida, dependiendo también de la intensidad de las lluvias, pero siendo una constante todos los años, perdiéndose vidas humanas y teniendo que invertir cantidades importantes de dinero en reparar o mitigar áreas que en algunos casos vuelven a presentar los mismos problemas con el tiempo.

A eso se le suma la presencia de los volcanes activos: el Volcán de San Salvador y la Caldera de Ilopango que potencialmente pueden activarse o provocar flujos de escombros (Major et al., 2004; Sheets, 2004; Sofield, 2004) y afectar seriamente la actividad económica y social de la metrópoli de El Salvador, debido a la alta concentración de población (figura 1).

La problemática se ha incrementado en los últimos años, con lluvias relacionadas con los huracanes o depresiones tropicales como el Mitch (1998), Stan (2005), Ida (2009), Alex (2010), Agatha (2010) y 12-E (2011); así como los terremotos en 1986 y 2001, principalmente (Evans $\&$ Bent, 2004). Esto se da especialmente en las tefras volcánicas llamadas "Tierra Blanca Joven" (TBJ) producto de la última erupción pliniana de la Caldera de Ilopango, cuyos productos son una intercalación de estratos de caída, flujos piroclásticos y oleadas piroclásticas o surges (Hernández, 2004; Jibson et al. 2004; Rolo et al. 2004). Estos fenómenos hacen que el país retroceda económicamente y socialmente, ya que se necesitan fondos del presupuesto nacional y hasta préstamos internacionales, para mitigar los efectos de las emergencias cada año, atrasando el desarrollo de todo el país y dejando en la pobreza a las personas afectadas, siendo difícil que vuelvan a su condición económica anterior. Esta situación se ha dado debido al poco conocimiento de los materiales geológicos en que se asentó la capital, ya que la urbanización se expandió de manera desordenada y sin control. En el resto del territorio hay presencia de otros materiales volcánicos cuyas propiedades no han sido estudiadas a profundidad, por lo que es primordial identificar los que son problemáticos y realizar los estudios correspondientes, cuando se proyecte una intervención antrópica o un cambio de uso de suelo; de manera que se pueda conocer de antemano la tecnología adecuada y las áreas en donde hay que tomar consideraciones puntuales.

En El Salvador hubo un repunte en la investigación antes de los años 80 , siendo éste interrumpido por la guerra civil. Actualmente hay escasez de profesionales preparados en las diferentes disciplinas de las ciencias de la tierra (Rose et al., 2004; González et al, 2004). Por esta razón se tiene poco conocimiento en disciplinas como geotecnia, hidrogeología, sismicidad, geología, geomorfología, hidrología, amenazas entre otras, lo que ocasiona que se utilice información desactualizada del territorio y frecuentemente de sitios que no corresponden con el que se esta estudiando; además los 


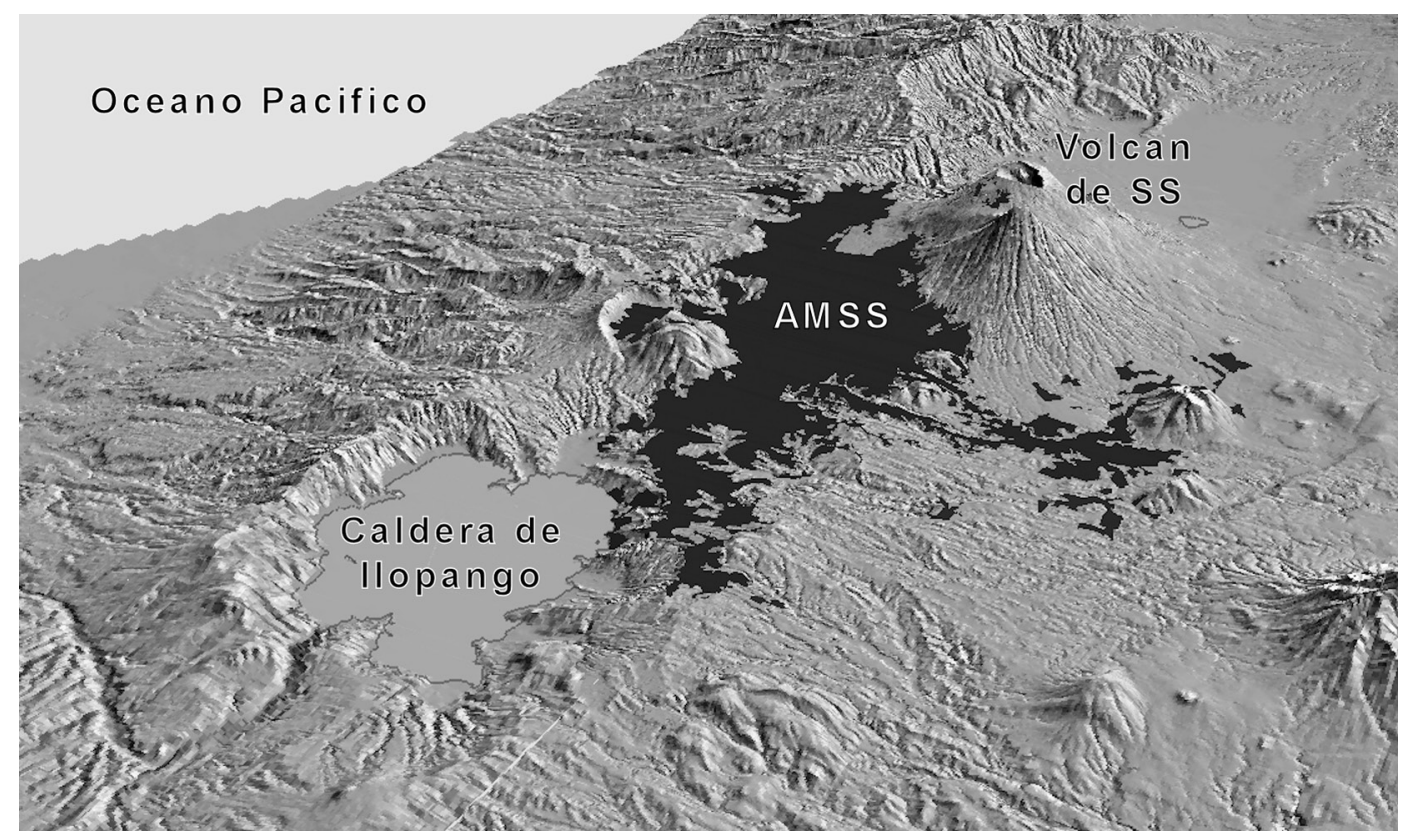

Fig. 1: Mapa de relieve del Área Metropolitana de San Salvador (AMSS), visto desde ENE. El área urbana esta en color negro (OPAMSS, 2008), el AMSS está rodeado por el volcán de San Salvador y Caldera de Ilopango. (Modificado de Lexa et al., 2011).

estudios presentados son bastante escuetos e incluso se presenta información que no concuerda con la realidad. A eso se le suma la limitante de no trabajar con una escala adecuada. Esta situación se ve reflejada en la problemática que se vive actualmente en el AMSS, ya que al no conocer el entorno natural o al tratar de bajar los costos de un proyecto evitando invertir en investigación, se puede llegar a tomar decisiones erradas, que con el tiempo afectan a un proyecto haciendo que la reparación sea más cara que si se hubiera hecho una investigación adecuada.

Los estudios recomendados para una obra civil dependerán de su ubicación, magnitud, tipo y su importancia, teniendo que tomar en cuenta que toda obra civil se apoya en suelo o en roca, esto hace imprescindible (Vásquez \& Huesca, 2008) que se conozca las propiedades geológicas, litológicas, geomorfológicas, hidrológicas, hidrogeológicas, geodinámicas, estructurales y geotécnicas que podrían llegar a afectar la obra. El conocer estas propiedades es el punto de partida para poder proyectar una obra civil.

\section{TIERRA BLANCA JOVEN}

Las rocas volcánicas que conforman la superficie del AMSS (figuras 2 y 3 ) están, en su mayoría, incluidas en la formación San Salvador, producto de los volcanes pertenecientes al frente volcánico de América Central (Plioceno-Cuaternario) (Lexa et al., 2011). Hernández (2008) describe la estratigrafía del AMSS y sus características; los estratos más importantes son: TB4, TB3, TB2 (entre ellos existen paleosuelos) y Tierra Blanca Joven (TBJ), que son productos eruptivos de la Caldera de Ilopango. Además G1, G2, así como, diferentes flujos de lava y tefras que pertenecen al estratovolcán de San Salvador. El basamento de la formación San Salvador está compuesto por los productos de las calderas y los volcanes de la formación Cuscatlán y los restos de estratovolcanes andesíticos de la formación Bálsamo (Lexa et al., 2011).

El espesor de las tefras de la formación San Salvador se reduce y su granulometría cambia a medida que se alejan de su centro de origen (o 
TBJ

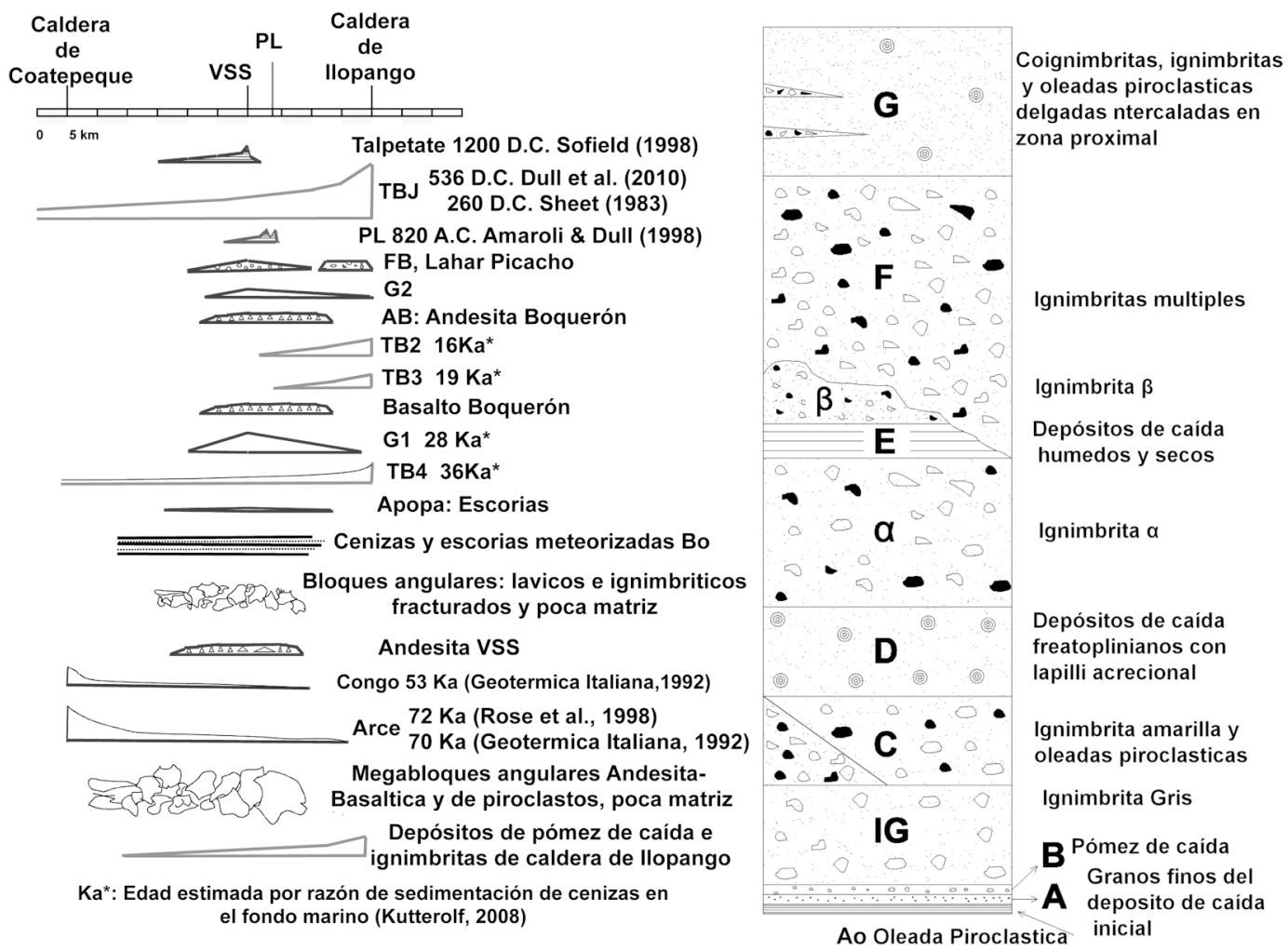

Fig. 2: Secuencias estratigráficas. (A) Depósitos volcánicos explosivos y efusivos del AMSS; PL: Plan de la Laguna, FB: Flujo de Boquerón, VSS: Volcán de San Salvador, TBJ: Tierra Blanca Joven, TB: Tierra Blanca (Modificado de Hernández, 2008). (B) Estratigrafía de TBJ (Modificado de Hernández, 2004).

foco emisor). Además, su distribución depende de la dirección de los vientos, los procesos erosivos y la explosividad durante la erupción. Según Francis \& Oppenheimer (2004) el radio de dispersión de los depósitos piroclásticos tiene que ver con la altura de la columna eruptiva; para las columnas mas grandes, la zona de difusión horizontal se puede extender en contra el viento formando un hongo asimétrico; para las columnas pequeñas la columna eruptiva se inclina a favor del viento.

La región mas inestable del AMSS (Figura 4) corresponde con los depósitos de espesor importante de la tefra volcánica llamada Tierra Blanca Joven (TBJ), producto de la última erupción pliniana de la Caldera de Ilopango (536 D.C., Dull et al., 2010), cuyos productos son una intercalación de caídas, surges u oleadas piroclásticas, flujos piroclásticos y episodios de erupciones húmedas (freatomagmatica) y secas. Según Dull et al. (2010) el volumen de tefra del evento eruptivo que produjo la TBJ fue de aproximadamente $84 \mathrm{~km}^{3}$.

Rolo et al. (2004) indican que por lo general las laderas o taludes de Tierra Blanca Joven (TBJ) son verticales y sufren una gran cantidad de movimientos de ladera debido a las lluvias, erosión o a los terremotos (Figs 4, 5 y 6). Además de la problemática mencionada anteriormente, se puede añadir que la mayor parte de las tuberías de agua potable, aguas servidas y aguas pluviales se encuentran en mal estado y cuando fallan es posible esperar el colapso de calles o casas enteras (Fig. 6B). Los depósitos piroclásticos TBJ (Hernández, 2004) consisten principalmente de fragmentos de vidrio volcánico que forman cenizas de arena fina 


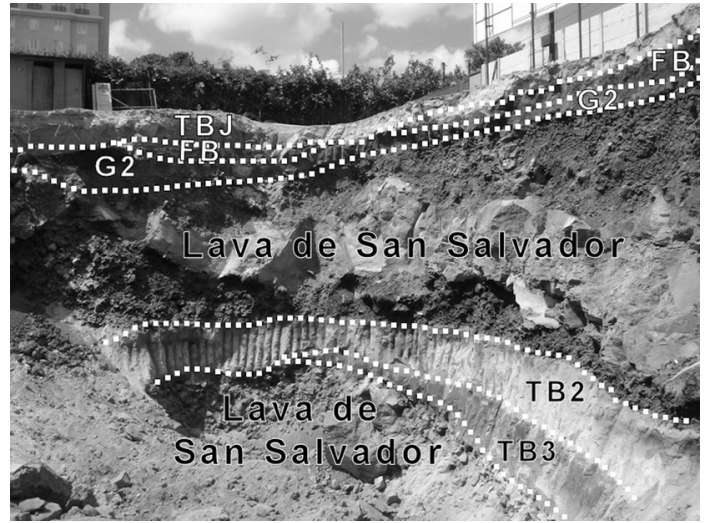

Fig. 3: Estratigrafía de la porción superior de la Formación San Salvador, en el lado occidental del AMSS (Zona Rosa, Colonia San Benito). y tamaño limo (grandes cantidades), fragmentos de pómez y líticos (tamaño grava, arena y grava); polvo volcánico y cristales en pequeña cantidad (tamaño arena y limo).

De acuerdo con la descripción de Hernández (2004), los depósitos TBJ están constituidos por las siguientes unidades: "A y Ao: depósitos de caída inicial y oleada piroclástica respectivamente $(\leq 10 \mathrm{~cm})$; B: depósitos de caída de pómez de tipo pliniano $(\leq 10 \mathrm{~cm})$; IG: ignimbrita gris con espesor de hasta $9 \mathrm{~m}$, en parte cementado por sulfatos y silicatos de cloruro de sodio, por lo tanto, más consolidado; $\mathrm{C}$ : compuesto por flujo piroclástico color amarillo y oleadas piroclásticas con un espesor de hasta 9 metros y en parte cementado por sulfatos y silicatos de cloruro de sodio, por lo

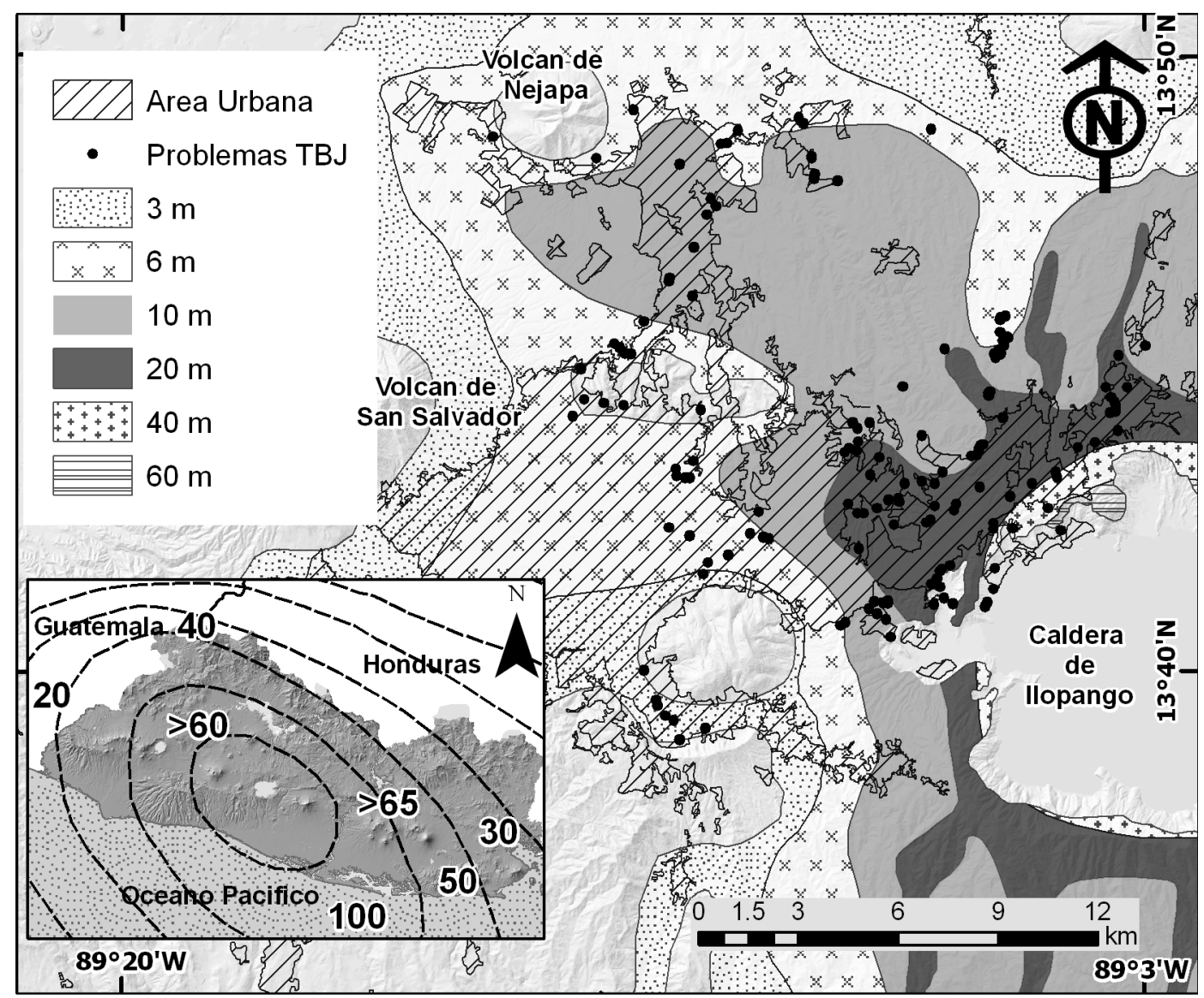

Fig. 4: Espesor de flujos piroclásticos de TBJ en metros. El recuadro muestra mapa de isopacas de tefras de TBJ con espesores en $\mathrm{cm}$ (Modificado de Dull et al, 2010). Los principales problemas de erosión y movimientos de ladera esta marcados por los puntos negros (OPAMSS, 2011). 


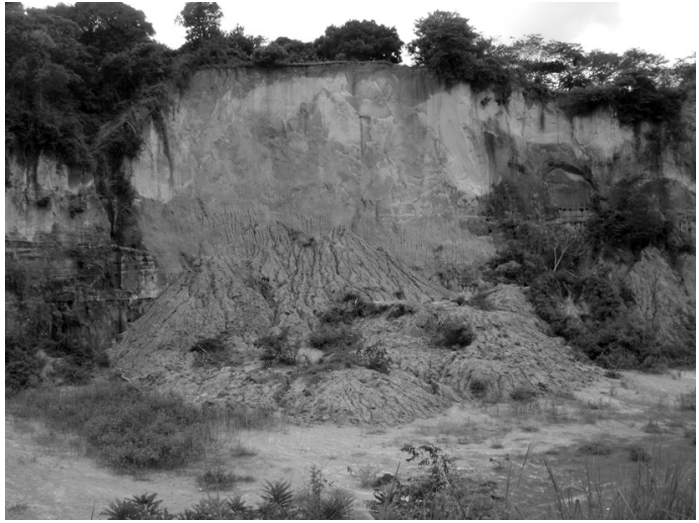

Fig. 5: Movimiento de ladera en TBJ (combinación de derrumbe y volcamiento) en escarpes de quebrada, sector corresponde a cuenca alta de río Las Cañas. que es relativamente más consolidado; D: depósito de ceniza fina, con presencia de pómez, lapilli acrecional, no consolidado en las zonas distales y media, pero cementado en la zona proximal ( $\leq$ $8 \mathrm{~m}) ; \alpha$ : flujo piroclástico con una matriz rica de cenizas, pómez y líticos, cementada en la base por sulfatos y silicatos, el resto de la unidad es no consolidada $(\leq 15 \mathrm{~m})$, E: depósitos de surges $\mathrm{u}$ oleadas piroclásticas secos y húmedos $(\leq 3 \mathrm{~m}), \beta$ : flujo piroclástico compactado con abundante matriz fina, pómez y presencia moderada de líticos $(\leq 4 \mathrm{~m}), \mathrm{F}$ : depósitos caóticos de flujo de pómez de espesor variable, desde menos de $1 \mathrm{~m}$ en las elevaciones (a 8-12 km de distancia de la caldera), hasta 20 - $60 \mathrm{~m}$ cerca de la Caldera de Ilopango, los bloques de pómez se concentran en la parte
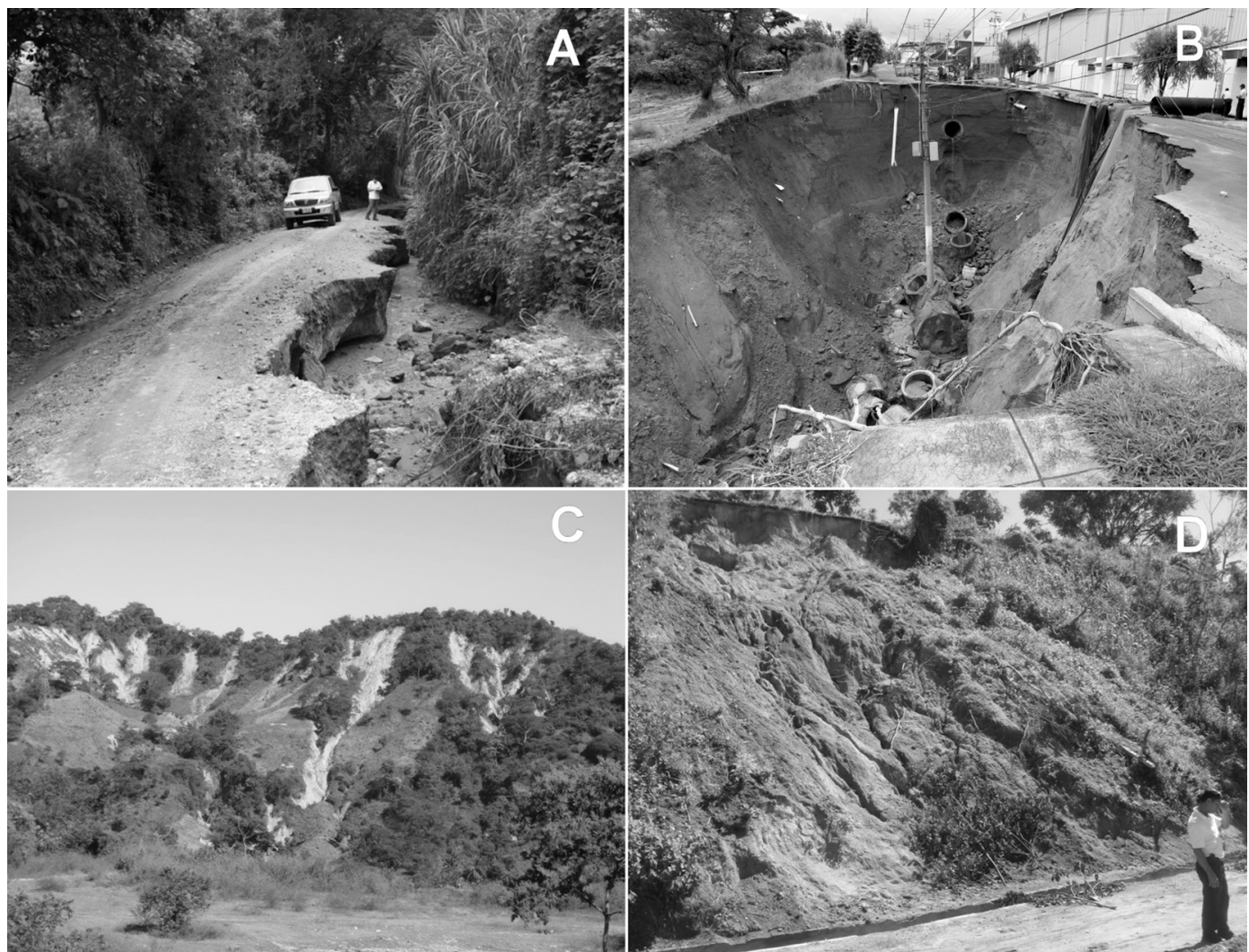

Fig. 6: Problemas en Tierra Blanca Joven (TBJ), (A) erosión en camino paralelo en margen norte de Caldera de Ilopango; (B) colapso en zona urbana de cuenca alta de río Las Cañas, asociado a disminución de nivel de lecho de quebrada y posterior erosión retrograda que provoco falla de sistema de tuberías; (C) movimientos de ladera (flujos) en laderas cercanas a margen oeste de Caldera de Ilopango; (D) flujo superficial, $4 \mathrm{~km}$ al norte de Caldera de Ilopango. 

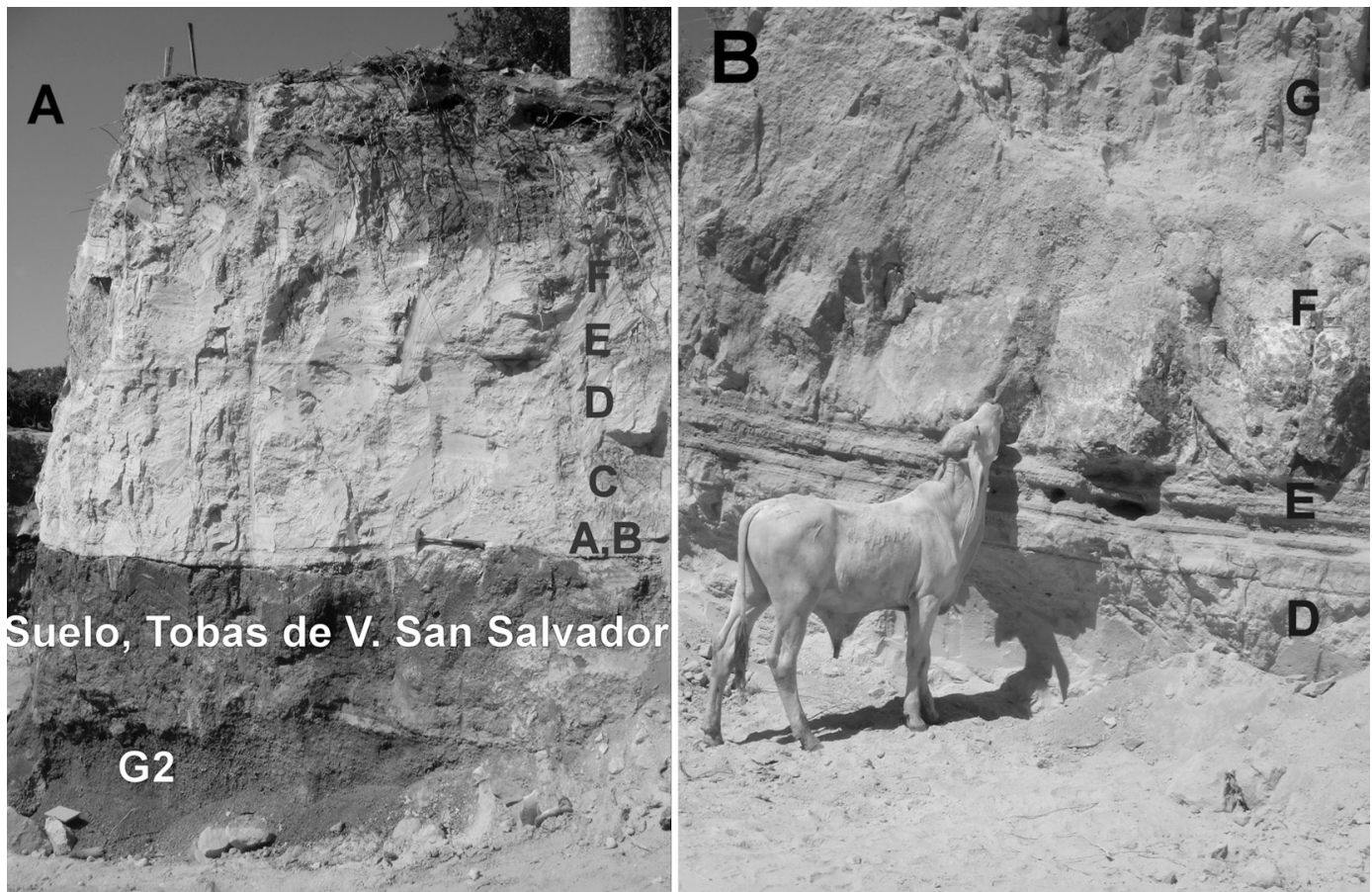

Fig. 7: Taludes casi verticales de Tierra Blanca Joven (TBJ) que se mantienen debido a la succión y cementación; se observa estratigrafía casi completa (flujos piroclásticos, caídas y surges). En fotografía B hay presencia de costra de minerales producidos por evaporación en la Unidad F.

superior y los líticos se concentran en la parte inferior, G: tobas finas con lapilli acrecional - depósitos de co-ignimbritas y flujos piroclásticos $(\leq 15$ $\mathrm{m}$ cerca de la Caldera de Ilopango, hasta menos de 1 m a 20 kilómetros de distancia)" (Figs 2 y 7).

Los surges u oleadas piroclásticas y los depósitos de flujos piroclásticos tienen mayor espesor en las depresiones. Dicho espesor también se incremento debido a la redepositación singenética por inundaciones (Lexa et al, 2011) y a que los procesos subsiguientes de erosión retransportaron las tobas sueltas de las crestas y laderas.

Šebesta \& Chávez (2010) describen la presencia de importantes áreas de badlands en TBJ, siendo terrenos con alta densidad de red de drenaje. Los badlands se originan en los depósitos de caída y flujos piroclásticos de TBJ, donde la erosión planar, de surcos y de barrancos, es común e intensa; siendo la susceptibilidad a los movimientos de ladera alta. Un problema actual en el AMSS es la urbanización de las zonas de badlands (Šebesta
\& Chávez, 2010), donde realizar rellenos es un procedimiento normal (Fig. 8). Durante los terremotos pasados, se dieron asentamientos pronunciados en zonas de relleno de TBJ, dándose daños estructurales graves (Bommer et al., 1998); en algunos casos TBJ es compactada inadecuadamente, dando lugar a problemas de erosión y colapso.

Según Šebesta \& Chávez (2010) la combinación de cambio en el nivel base, los cambios antropogénicos (urbanización, deforestación, extracción de arena de rio las Cañas), el clima (sequia, huracanes o depresiones tropicales) y la tectónica (se pueden observar fallas jóvenes en TBJ) son los principales controles externos de las altas tasas de erosión en la zona proximal de la Caldera de Ilopango, que afecta a la morfología y a la infraestructura civil cercana a ríos y quebradas; $\sin$ embargo no se conoce la proporción en que afecta cada control externo en la problemática actual. Por ejemplo, el nivel base de la cuenca del río Las Cañas es el lago artificial de Cerrón Grande (al 


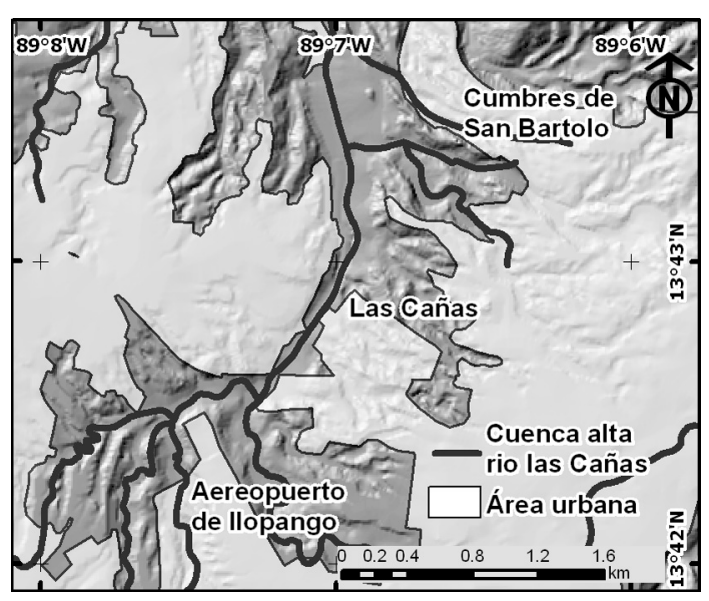

Fig. 8: Mapa de sombras en área de badlands en TBJ; ocupadas actualmente por proyectos de vivienda (Basado en cartografía 1:25,000, CNR, 1981).

norte del AMSS) y durante el año 2001 (González et al., 2004) un período de sequía cambio el nivel drásticamente, tal vez este evento inició un ciclo de cambio y de búsqueda del equilibrio de todo el sistema de drenaje, provocando cambios de nivel en las quebradas de la cuenca alta, donde predominan espesores importantes de TBJ y donde se ha dado erosión vertical de hasta $8 \mathrm{~m}$ (2008-2010), erosión lateral y conformación de meandros (Figs 9 y 10).

\section{Conocimiento geotécnico actual de Tierra Blanca Joven (TBJ)}

Ali (2011) dice que en muchas partes del mundo los suelos están clasificados como "problemáticos" debido a las dificultades que se producen antes y después de la construcción de las fundaciones o las carreteras, así como en las laderas debido a la deformación excesiva que ocurre, lo cual puede producir expansión o colapso. Problemas similares pueden ocurrir en los rellenos o suelo compactado, por lo que estos suelos deben ser identificados antes de planificar construir sobre ellos.

Desde 1936, con la "Primera Conferencia Internacional de Mecánica de Suelos e Ingeniería de Cimentaciones" se ha mostrado interés en el comportamiento de los suelos ubicados tanto arriba como abajo del nivel freático (parcialmente saturados y saturados respectivamente), construyéndose desde ese entonces las bases de la Mecánica de Suelos (Fredlund, 1997). Sin embargo en un inicio, las primeras investigaciones se centraron más en los suelos saturados debido a que estas se hicieron en zonas donde el clima es fresco o húmedo, donde la zona vadosa o parcialmente saturada está relativamente cerca de la superficie; a esto se le suma que, para los suelos parcialmente saturados ha tomado mayor tiempo desarrollar la tecnología adecuada para medir sus parámetros, así como, entender su comportamiento en campo y en laboratorio. Pero debido a que las obras civiles en gran parte del mundo (zonas áridas y semiáridas) están construidas sobre suelos parcialmente saturados y a la cantidad de problemas que presentan, los cuales son bastante onerosos, se han hecho avances importantes hasta la fecha. Fredlund \& Rahardjo (1993) llamaron a este tipo de suelos la "catástrofe oculta", porque en los Estados Unidos durante los años 70 y 80, miles de millones de dólares se perdieron relacionados con daños a la infraestructura construida sobre estos materiales geológicos.

Normalmente, en El Salvador todos los diseños geotécnicos de TBJ utilizan el círculo de esfuerzos de falla de Mohr-Coulomb para la obtención de los parámetros de los materiales de la cohesión "c" y el ángulo de resistencia al corte " $\varnothing$ " haciendo uso de la caja de corte o equipo de triaxial (equipo para suelos saturados). Según Molina et al. (2009) los resultados más desfavorables para TBJ (área proximal: unidad G), utilizando la caja de corte, es cuando la muestra está saturada y la condición es no drenada-no consolidada (UU).

Guzmán \& Melara (1996), Amaya \& Hayem (2000), Rolo et al. (2004), Hernández (2004); Molina et al. (2009), Avalos \& Castro (2010) y Ascencio \& Zúniga (2010) estudiaron los aspectos geotécnicos y litológicos de la Tierra Blanca Joven (TBJ). Todos los autores caracterizan a TBJ como arenas limosas y limos arenosos, algunos valores de cohesión y el ángulo de fricción de las unidades superficiales de TBJ (Chavez et al., 2012, Fig. 14) presentan dispersión en los datos. Dichos autores concluyen que si una muestra (no 


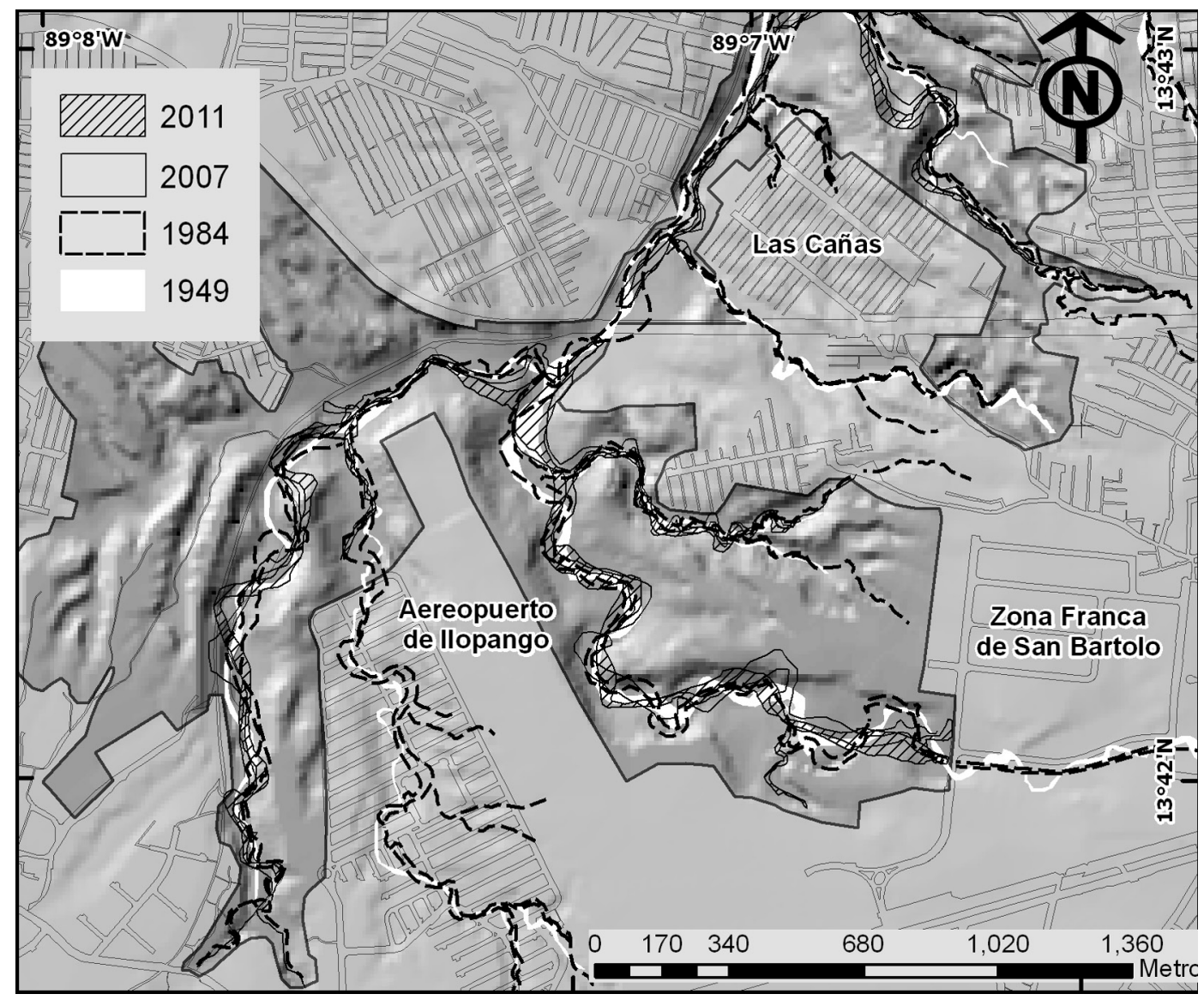

Fig. 9: Cambios en drenaje de cuenca alta de río Las Cañas (figura 8), tomado de fotografías aéreas de 1949, 1984 y de Google Earth.

alterada o alterada) es saturada, hay una disminución de la resistencia al corte, si se compara con una muestra de humedad natural.

En El Salvador durante las dos estaciones del año (época seca y época lluviosa) el nivel de las aguas subterráneas en las zonas más urbanas se mantiene de $35 \mathrm{~m}$ de profundidad (Rolo et al., 2004), esto significa que la mayoría de los suelos en el país son parcialmente saturados (presencia de agua, aire y suelo) y hay fuerzas capilares que actúan sobre la estructura del suelo haciendo que una "cohesión aparente" o succión mejore la resistencia del suelo, la cual se pierde cuando es saturado o debido a terremotos/vibraciones. Chamra et al. (2010) realizaron ensayos preliminares de absorción de agua en la TBJ, lo cual oscila entre $40 \%-45 \%$. El resultado de capilaridad en una muestra de unidad " $D$ " de TBJ en la zona proximal se presenta en la figura 11 .
Para un suelo saturado, el estado de esfuerzos es definido por el esfuerzo efectivo $\sigma^{\prime}=\sigma$-uw lo cual es válido solamente cuando el suelo está completamente saturado o completamente seco. Para los suelos parcialmente saturados como TBJ (Fredlund \& Rahardjo, 1993) se hace uso de dos conjuntos de variables independientes de esfuerzo (las cuales son las más usadas): El esfuerzo neto: $\sigma-u_{a}$ y la succión: ua- $u_{w}$. Donde $\sigma$ es el esfuerzo total, uw es la presión de poros de agua (negativa) y ua es la presión de poros de aire. Rahardjo \& Leong (1997) expresan que las curvas características de suelo-agua para suelos parcialmente saturados (curva donde se presenta cambio de contenido de agua con respecto a cambio de succión y que es muy usada para caracterizar estos suelos) juegan un rol similar a las curvas de consolidación de los suelos saturados, y pueden ser 


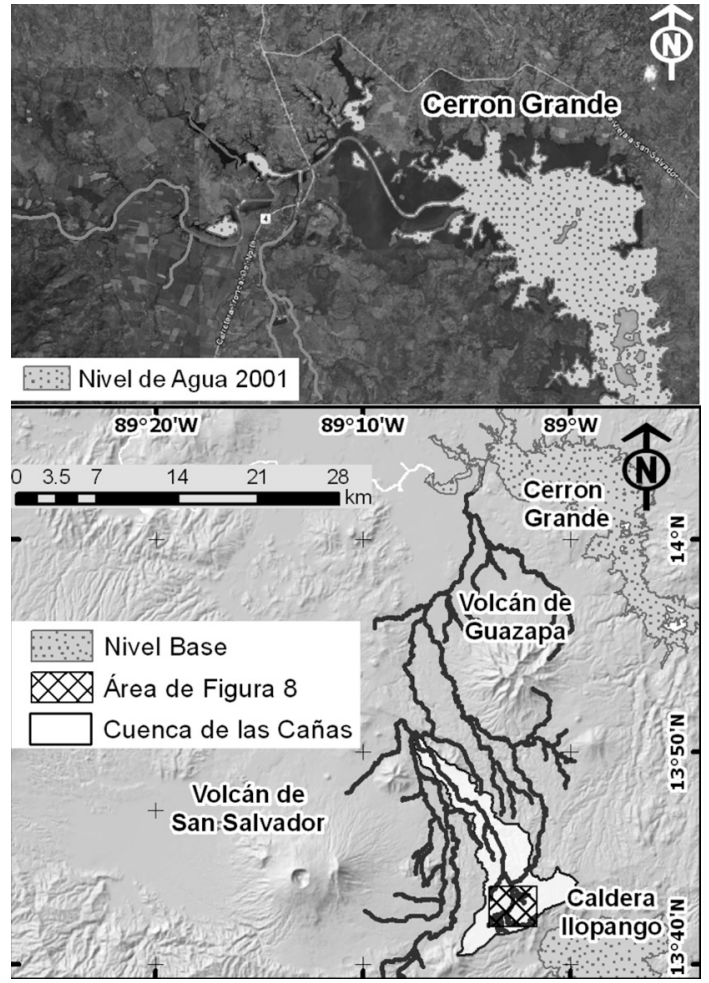

Fig. 10: Arriba se demarca en presa artificial Cerrón Grande el nivel de agua por cambios ocurridos durante el 2001, contra nivel del año 2005 (Google Earth). Abajo, situación de cuenca de Rio las Cañas (OPAMSS, 2010) con respecto a su nivel base (lago artificial Cerrón Grande).

usadas para obtener y estimar indirectamente la permeabilidad y el esfuerzo cortante. En la figura 12 se presentan valores de succión-humedad de TBJ de otros autores y nuevos resultados obtenidos con el papel filtro, con los cuales se presenta por primera vez de manera completa una curva característica de suelo-agua de TBJ (piroclastos de caída de Unidad G).

Según Rahardjo \& Leong (1997), la infiltración de las aguas de lluvia dentro de la zona parcialmente saturada, arriba del nivel freático es un problema típico de flujo de frontera en donde tienen que ver las características de suelo-agua y la permeabilidad de los suelos parcialmente saturados. Estas propiedades hidráulicas son las que controlan la profundidad y tasa de infiltración dentro de la ladera o talud, lo cual afectará los cambios en la presión de poros de agua y la estabilidad de la ladera o talud durante la lluvia.
TBJ-Unidad D

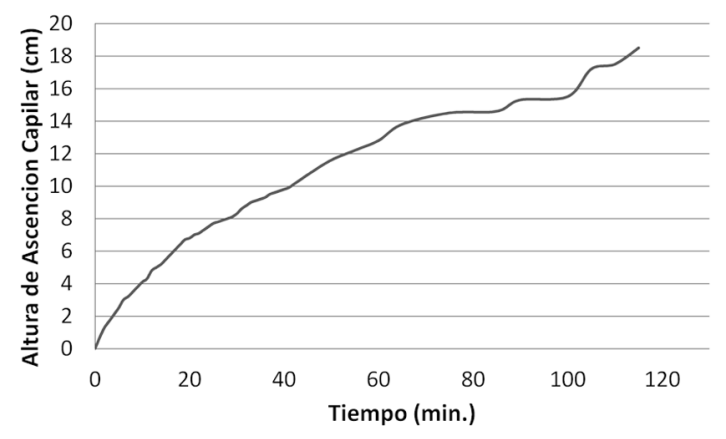

Fig. 11: Capilaridad en una muestra de unidad D de TBJ, que describe el tiempo de subida del agua en la muestra.

Rolo et al. (2004) concluyeron cuando se satura Tierra Blanca Joven (TBJ) hay una pérdida de volumen o colapso que ocurre de repente, siendo la posible causa del gran número de movimientos de ladera que se dan en el AMSS. Durante las lluvias y terremotos ocurren flujos superficiales y derrumbes, (Figs 5 y 6) los cuales son de pequeño a mediano volumen, pero que se dan con gran densidad en el territorio (Bommer et al., 1998, figuras 10, 18 y 19).

Los resultados para el índice de colapso (Figura 13) de Molina et al. (2009) en la zona proximal de la unidad " $G$ " de TBJ, oscilan entre moderado y severo (contenido de humedad de 13.3\%-20.1\%); de Ávalos \& Castro (2010) en la zona intermedia de la unidad "G", entre moderado y ligero, (contenido de humedad de $26.7 \%$ 36.7\%); de Ascencio \& Zúñiga (2010) en la zona proximal de la unidad "D", el índice de colapso fue clasificado como ligero (contenido de humedad de 13.6\%-17.2\%). Dicha información indica que hay una disminución de volumen o colapso cuando TBJ es sometido a una carga de $200 \mathrm{kPa}$ y luego saturado inmediatamente.

Resultados similares obtuvieron Rolo et al. (2004) al realizar la prueba de doble-odómetro para muestras inalteradas y remoldeadas (intactas y con humedad natural), ya que se observó que las muestras con humedad natural colapsan abruptamente cuando se cargan, en este caso con $1300 \mathrm{kPa}$, y luego son saturadas inmediatamente (Fig. 14).

Para complementar la caracterización, se estudiaron las unidades $\mathrm{D}, \mathrm{F}$ y $\mathrm{G}$ de TBJ utilizando el microscopio electrónico de barrido ambiental 


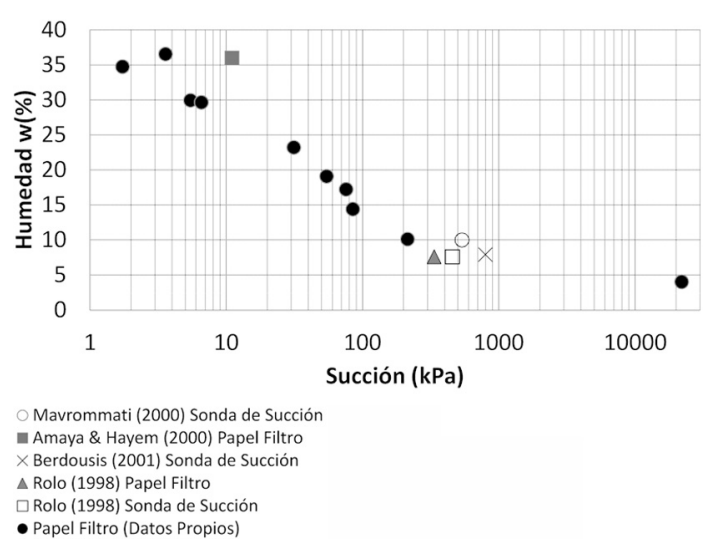

Fig. 12: Mediciones de succión en Tierra Blanca (Rolo et al., 2004 y datos propios).

(ESEM), algunos de los resultados se muestra en la figura 15. Los resultados son consistentes con las observaciones formuladas por Rolo et al. (2004) utilizando el microscopio electrónico de barrido, ya que hay una importante presencia de vacíos (donde el agua capilar puede estar presente), además, entre los granos no hay vínculos fuertes, lo que sugiere una estructura meta-estable. También con ESEM se detecto presencia de arcilla (esméctica) cubriendo a los minerales, lo cual fue corroborado con prueba de mineralogía en la fracción de arcilla. Esta presencia de minerales de arcilla en TBJ está en concordancia con los resultados de mineralogía y petrología en TBJ de Amaya \& Hayem (2000), donde se obtuvo presencia de esmectica (montmorillonita). Lo cual está de acuerdo con la definición de suelos colapsables, (Houston \& Houston, 1997; Charles \& Menzies, 2007), los cuales son suelos compuestos por limos y arenas finas con pequeñas cantidades de arcilla y que tienen baja densidad, pero son relativamente rígidos y fuertes en su estado natural. La cementación de los suelos colapsables puede consistir en arcilla seca, sales, óxidos, succión, fuerzas entre partículas en suelos arcillosos y en precipitados químicos, que pueden haber sido añadidos después de la depositación.

Guzmán \& Melara (1996), Rolo (1998), Amaya \& Hayem (2000), Hernández (2004) y Rolo et al. (2004) concluyeron que una unión débil debido a cementación y succión aumenta la resistencia de Tierra Blanca Joven (TBJ).
Actualmente no está claro con exactitud qué tipo de agentes de cementación actúan en TBJ. Amaya \& Hayem (2000) sugirieron que las esmectitas (montmorillonita) presentes en la TBJ podrían estar actuando como un agente de cementación. Hernández (2004) llegó a la conclusión de que la cementación por mineralización secundaria en TBJ está compuesta de sulfatos y silicatos. Además por procesos de evaporación del agua en el suelo (Figura 7B); el vapor transporta afuera de los taludes iones y cationes procedentes de los depósitos piroclásticos formando una costra de pocos milímetros de espesor donde predominan los sulfatos.

\section{CONCLUSIONES}

En la actualidad la Tierra Blanca Joven (TBJ), perteneciente a la formación San Salvador, es el estrato más problemático en el Área Metropolitana de San Salvador (AMSS) y donde se dan daños sociales, ambientales y económicos importantes. Entre los aspectos que tienen que ser investigados se pueden mencionar el comportamiento debido al cambio de contenido de humedad, incidencia y tipo de cementación, procesos de meteorización, evaporación, vibraciones y desequilibrio de procesos naturales de infiltración-evapotranspiración debido a la urbanización; ya que pueden ser condicionantes para la ocurrencia de movimientos de ladera, erosión, así como, del colapso de calles y de proyectos urbanísticos. El mecanismo de colapso o falla por derrumbe-volcamiento en TBJ fue descrito por Hernández (2004), pero esto no se ha estudiado con más detalle (al igual que los flujos superficiales en taludes y laderas) a pesar de la problemática constante que se genera en los barrancos, ríos y proyectos de vivienda.

En los suelos parcialmente saturados, como lo demuestran los resultados en Tierra Blanca Joven (TBJ), hay presencia e interacción entre las fases sólidas (partículas de suelo), de agua (presión de poros presenta valores negativos) y de aire, por lo que estas fases tienen que ser tomadas en cuenta para entender su estado de esfuerzos, la permeabilidad y el cambio de volumen; siendo importante profundizar aspectos como: la medición de la 


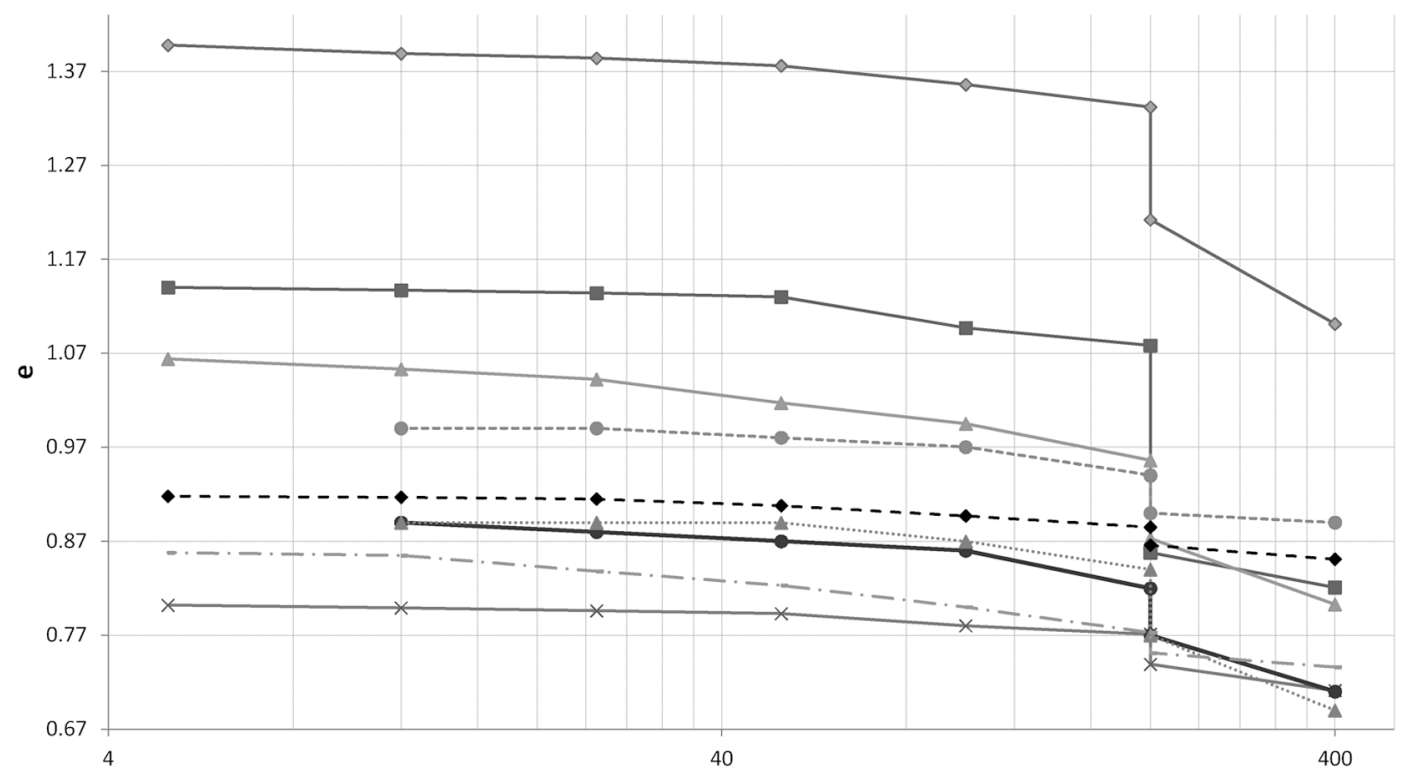

Esfuerzo Vertical $\mathrm{kPa}$

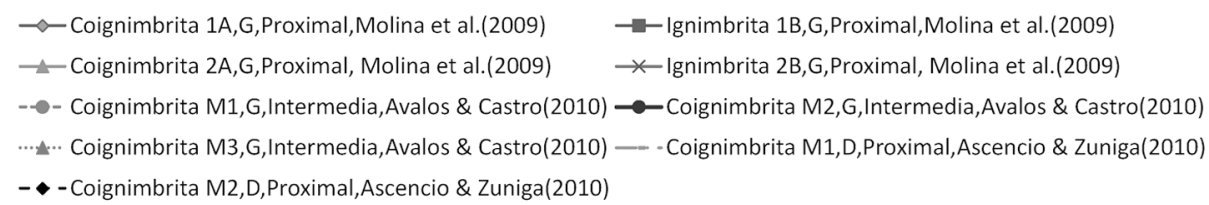

Fig. 13: Resultados de colapsabilidad de diferentes autores.

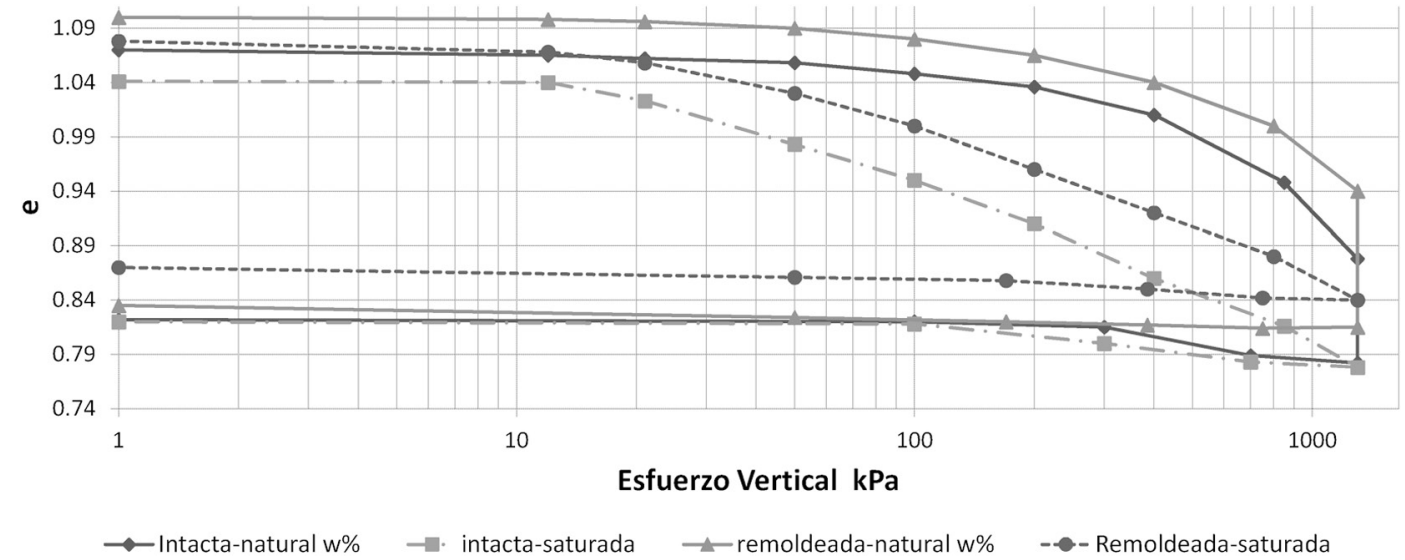

Fig. 14: Compresibilidad de TBJ obtenida con prueba del doble-odómetro. (Rolo et al., 2004). 

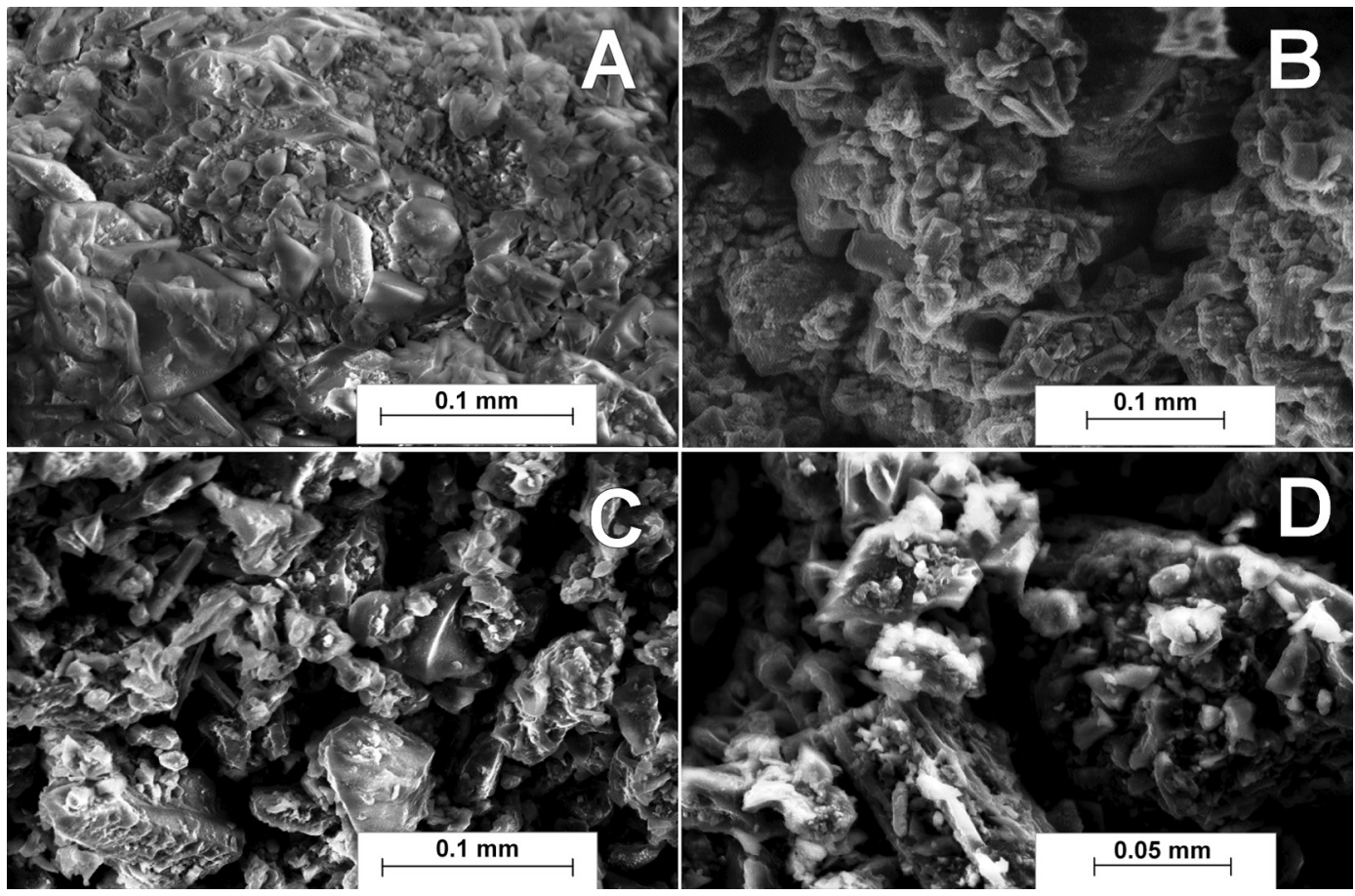

Fig. 15: Vista de unidades de TBJ haciendo usos de microscopio electrónico de barrido ambiental (ESEM): (A) unidad "D”; (B) unidad "F"; (C y D) Unidad "G".

succión; el esfuerzo cortante contra la succión; medición del coeficiente de permeabilidad contra la succión y la medición del cambio de volumen. Esto hace que el uso de equipo de laboratorio para obtener esta información sea necesario para caracterizar este tipo de suelos problemáticos y comprender su comportamiento.

El uso de tensiómetros de alta capacidad, así como el uso de otro equipo y técnicas como la del traslado de eje permiten medir presiones de poro de agua negativas de hasta $1500 \mathrm{kPa}$ (Marinho et al., 2008). Existen otras técnicas de medición indirecta de succión (Bulut \& Leong, 2008) usando medios primarios (psicrómetros), medios secundarios (método de papel filtro, figura 12), así como, medios terciarios (sensores de conductividad termal y sensores de conductividad eléctrica) los cuales tienen sus limitaciones y capacidades respectivas. Además hay métodos actuales para pruebas de laboratorio en suelos parcialmente saturados (Hoyos et al., 2008) usando sistemas cilíndricos de triaxial, incluyendo cambio de volumen y medición de rigidez; también se puede medir la rigidez con pequeñas deformaciones usando columnas resonantes y sistemas de elementos basados en doblado. El uso de equipo triaxial (medición de presión de poros de agua y de aire) puede ayudar en la caracterización esfuerzo-deformación.

Con el avance tecnológico y la ayuda de software geotécnico, se pueden tomar los valores obtenidos en campo y laboratorio; para simular diferentes escenarios en laderas o taludes y conocer el tipo de superficie de falla que se podría esperar; o comparar propuestas de mitigación, las cuales se pueden contrastar con el comportamiento real en campo. El entendimiento y modelamiento del comportamiento y propiedades de los suelos parcialmente satura- 
dos es vital para El Salvador ya que en la actualidad se hace uso de la mecánica de suelos para materiales saturados (esfuerzo efectivo) tanto en la enseñanza universitaria como en el diseño de las obras de construcción, conformación de taludes y obras de mitigación, por lo que una actualización es necesaria en la filosofía de diseño geotécnico, en el ordenamiento territorial, mejoramiento de suelos y en los reglamentos de construcción.

La identificación de las capas problemáticas antes de un cambio de uso del suelo o de proyectar una construcción civil, puede ayudar a decidir la estrategia de gestión del riesgo más adecuada para evitar y estar preparados frente a los problemas futuros. Esto tiene que incluir mapeo de ingeniería geológica (Chavez et al., 2012) que contenga información de geomorfología, geología, sismicidad, hidrogeología, riesgos geológicos e información geotécnica y ayuden en la toma de decisiones para la planificación de proyectos.

\section{AGRADECIMIENTOS}

Deseamos reconocer apoyo recibido de la Oficina de Planificación del Área Metropolitana de San Salvador (OPAMSS), Universidad Técnica Checa en Praga (ČVUT), Dirección General del Observatorio Ambiental del Ministerio de Medio Ambiente y Recursos Naturales de El Salvador, Facultad de Ciencias Agronómicas y Escuela de Ingeniería Civil de la Universidad de El Salvador. Agradecemos a las personas que revisaron este artículo y editores, cuyos comentarios mejoraron su calidad.

\section{REFERENCIAS}

ALI, M.M., 2011: Identifying and analyzing problematic soils.- Geotech. and Geol. Engin. 29(3): 343-350.

AMAYA, C. \& HAYEM, E., 2000: Introducción al estudio de suelos parcialmente saturados e inicio de la caracterización de la
Tierra Blanca del AMSS.- 147 págs. Univ. Centroamericana José Simeón Cañas, San Salvador, El Salvador [Tesis Lic.].

ASCENCIO, N. \& ZÚNIGA, D., 2010: Tierra Blanca Joven: caracterización geológica y geotécnica de la unidad "D".- 97 págs. Univ. Centroamericana José Simeón Cañas, San Salvador, El Salvador [Tesis Lic.].

AVALOS, J. \& CASTRO, R., 2010: Caracterización geológica y geotécnica de la unidad "G" de Tierra Blanca Joven.- 95 págs. Univ. Centroamericana José Simeón Cañas, San Salvador, El Salvador [Tesis Lic.].

BOMMER, J., SALAZAR, W. \& SAMAYOA, R., 1998: Riesgo sísmico en la región metropolitana de San Salvador.- 78 págs. PRISMA, San Salvador [Inf. interno]

BULUT, R. \& LEONG, E.C., 2008: Indirect measurement of suction.- Geotech. and Geol. Engin. 26(6): 633-644.

CHAMRA, S., CHAVEZ, J.A., HERNÁNDEZ, E.W., LEXA, J., SCHRÖFEL, J., ŠEBESTA, J. \& VALENTA, J., 2010: Estudios especiales de reconocimiento de las condiciones geológicas para la reducción de los riesgos naturales en el Área Metropolitana de San Salvador, El Salvador.- 108 págs. OPAMSS-Servicio Geológico Checo, San Salvador [Inf. interno].

CHAVEZ, J., VALENTA, J., SCHRÖFEL, J., HERNANDEZ, W. \& ŠEBESTA, J., 2012: Engineering geology mapping in the southern part of the Metropolitan Area of San Salvador.- Rev. Geol. Amér. Central, 46: 161-178.

DULL, R., SOUTHON, J., KUTTEROLF, S., FREUNDT, A., WAHL, D. \& SHEETS, P., 2010: Did the TBJ Ilopango eruption cause the AD 536 event?.- Amer. Geophys. 
Union, Fall Meeting. San Francisco, California (poster \#V13C-2370).

EVANS, S. \& BENT, A., 2004: The Las Colinas landslide, Santa Tecla: A highly destructive flowslide triggered by the January 13 , 2001, El Salvador earthquake.- Geol. Soc. Amer., Spec. Paper, 375: 25-37

FRANCIS, F. \& OPPENHEIMER, C., 2004: Volcanoes [2a ed.].- 521 págs. Ed. Oxford University Press, Nueva York.

FREDLUND, D.G. \& RAHARDJO, H., 1993: Soil mechanics for unsaturated soils.-510 págs. Ed. Wiley-Interscience Publications, Nueva York.

FREDLUND, D.G., 1997: An introduction to Unsaturated Soil Mechanics.- En: HOUSTON, S. \& FREDLUND, D.(ed.): Unsaturated soil engineering practice.Amer. Soc. Civil Engineers, Geotech. Spec. Pub. 68: 1-37.

GONZALEZ, L., ROMANO, L. \& SALAMANCA, L., 2004: Risk and disasters in El Salvador: Economic, environmental, and social aspects.- Geol. Soc. Amer., Spec. Paper, 375: 461-470

GUZMÁN, M.A., \& MELARA, E., 1996: Propiedades ingenieriles del suelo del área metropolitana de San Salvador, El Salvador.- Rev. ASIA, 122: 14-22.

HERNÁNDEZ, E.W., 2004: Características geotécnicas y vulcanológicas de las tefras de Tierra Blanca Joven de Ilopango, El Salvador.- 115 págs. Univ. Politécnica de El Salvador, San Salvador [Tesis M.Sc.].

HERNÁNDEZ, E.W., 2008: Aspectos geológicos que influyen en las aguas subterráneas y en la respuesta sísmica del Área Metropolitana de San Salvador.- 19 págs. SNET, San Salvador [Inf. interno].
HOUSTON, S.L. \& HOUSTON W.L., 1997: Collapsible Soil Engineering.- En: Houston, S. \& Fredlund, D. (ed.): Unsaturated soil engineering practice.Amer. Soc. Civil Engineers, Geotech. Spec. Pub. 68: 170-199.

HOYOS, L.R, LALOUI, L. \& VASALLO, R., 2008: Mechanical testing in unsaturated soils.- Geotech. Geol. Engin. 26 (6): 675-689.

JIBSON, R., CRONE, A., HARP, E., BAUM, R., MAJOR, J., PULLINGER, C., ESCOBAR, D., MARTINEZ, M. \& SMITH, M., 2004: Landslides triggered by the 13 January and 13 February 2001 earthquakes in El Salvador.- Geol. Soc. Amer., Spec. Paper, 375: 69-88

LEXA, J., ŠEBESTA, J., CHÁVEZ, J.A., HERNANDEZ, W. \& PÉCSKAY, Z., 2011: Geology and volcanic evolution in the southern part of the San Salvador Metropolitan Area.- J. Geosci. 56: 105-140.

MAJOR, J., SCHILLING, S., PULLINGER, C. \& ESCOBAR, D., 2004: Debris-flow hazards at San Salvador, San Vicente and San Miguel volcanoes, El Salvador.- Geol. Soc. Amer., Spec. Paper, 375: 89-108

MARINHO F., TAKE, W. \& TARANTINO, A., 2008: Measurement of matric suction using tensiometric and axis translation techniques.- Geotech. and Geol. Engin. 26(6): 615-631.

MOLINA, B., PÉREZ, G. \& VÁSQUEZ, M., 2009: Caracterización geotécnica de las tefras Tierra Blanca Joven: unidad " $G$ " en la zona proximal y obras de protección.- 133 págs. Univ. Centroamericana José Simeón Cañas, San Salvador [Tesis Lic.]. 
CHARLES, W.W., \& MENZIES, B., 2007: Advanced unsaturated soil mechanic and engeneering.- 654 págs. Taylor and Francis, Londres.

RAHARDJO, H. \& LEONG, E.C., 1997: Soil water characteristic curves and flux boundary problems.- En: HOUSTON, S. \& FREDLUND, D. (ed.): Unsaturated soil engineering practice.- Amer. Soc. Civil Engineers, Geotech. Spec. Pub. 68: 88-112.

ROLO R., BOMER, J., HOUGHTON, B., VALLANCE, J., W., BERDOUSIS, MAVROMMATI, P., C. \& MURPHY, W., 2004: Geologic and engineering characterization of Tierra Blanca pyroclastic ash deposits.- Geol. Soc. Amer., Spec. Paper 375: 55-67

ROSE, W., BOMMER, J. \& SANDOVAL, C., 2004: Natural hazards and risk mitigation in El Salvador: An Introduction.- Geol. Soc. Amer., Spec. Paper 375: 1-4.

SHEETS, P., 2004: Apocalypse then: Social science approaches to volcanism, people, and cultures in the Zapotitan Valley, El Salvador.- Geol. Soc. Amer., Spec. Paper 375: 109-120.

SOFIELD, D., 2004: Eruptive history and volcanic hazards of Volcan San Salvador.- Geol. Soc. Amer., Spec. Paper 375: 147-158.

ŠEBESTA, J. \& CHAVEZ, J., 2010: Cartografía y evaluación para estudiar los procesos erosivos en el Área Metropolitana de San Salvador.- 85 págs. OPAMSS-Embajada de Republica Checa en Costa Rica [Inf. interno].

VÁSQUEZ, R. \& HUESCA, G., 2008: Geología Aplicada a la Ingeniería Civil.- 255 págs. Editorial Limusa, México. 